\title{
The Impact of Climate Change on Yemen's National Stability
}

\author{
Bojian Zhang \\ School of Department of Mechanical Engineering, North China Electric Power Univercity, Baoding \\ 071003, China \\ 873734968@qq.com
}

Keywords: Fuzzy Analytic Hierarchy Process (FAHP), Sensitivity test, FDS

\begin{abstract}
In this paper, we have developed an FDS that is a measure of national vulnerability. From the FDS, we can judge whether the fragile state of the country is fragile or vulnerable or stable. We use Fuzzy Analytic Hierarchy Process (FAHP) to construct an evaluation model to evaluate the vulnerability and measure the impacts of climate change. We select vulnerability as a primary indicator, economy, politics and society as secondary indicators, there are three level three indicators under each level indicator. Correlation between vulnerability and climate is obtained by the correlation coefficient method to conclude that climate is indirectly affected by the vulnerability. Climate change indirectly affects the vulnerability of a country through its impact on three-level indicators, such as per capita GDP and per capita resources. We found that climate change exacerbated the country's vulnerability by affecting GDP per capita, unemployment rate, CPI, per capita resources and peace index. We came to the conclusion by calculating: FDS affected by climate is greater than FDS that is not affected by climate in the same period, or that if Yemen is not affected by climate, its vulnerability will be reduced.
\end{abstract}

\section{Introduction}

Somalia, on the eastern most continent of Africa, has the longest coastline in Africa. [1] As a result of years of civil strife, industrial and agricultural production and infrastructure have been severely damaged, and about 43 per cent of the population lives on less than \$ 1 a day [2]. Afghanistan, situated in the heart of Asia, has experienced serious brain drain due to military interventions in other countries, with illiteracy rates as high as $65 \%$ in the country [3]. After 911 , the theory of the fragile state associated with terrorist organizations received more and more attention. Fragile countries mean state disorder. This disorder is reflected in the political, economic, social and other aspects.

We hope to establish a model that can be used to analyze a country's vulnerability and help to improve the country's vulnerability. We hope that in the future development model, some intervention measures will be put forward to enhance the stability of the fragile countries and contribute to world peace and stability

\section{General Assumptions and Variable Descriptions}

- The impact of climate change on various factors in one country is negligible. Because the factors we are considering are the most basic factors that measure the level of a country, the impacts of climate change often involve many factors. In other words, the importance of these factors is changing at the same time and we consider their weights It is unchanged.

- For the impact of climate change, we only consider that these effects affect only some specific factors of vulnerability. The impact of climate change is widespread, but the impact is very small for a number of factors, such as human rights and the rule of law, and the corruption index. These effects are negligible.

- When analyzing specific countries, we ignore the small probability of natural disasters that occur in this country. 


\section{Primary Measurement System}

\subsection{Select Factors}

Drawing on the evaluation factors in FSI, we consider three second-level factors, Economic indicators (EI), Social indicators (SI) and Political indicators (PI), each of which contains three sub-factors, as shown in Figure 1.

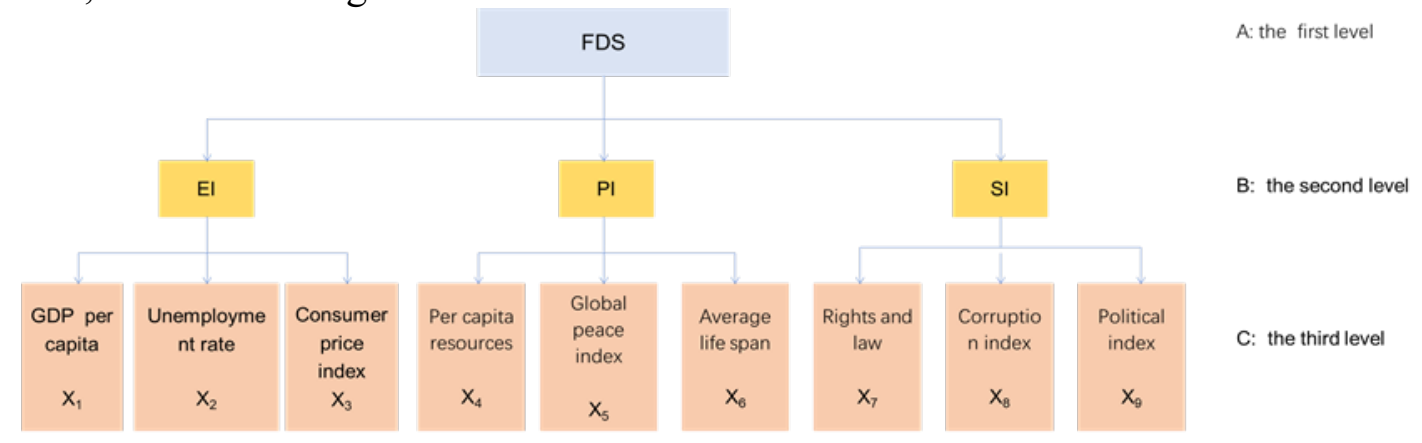

Figure 1 Hierarchy figure

We assume that climate change affects only GDP per capita (X1), unemployment (X2), CPI (X3), per capita resources (X4), peace index (X5)

\subsection{Measuring the Fragility by Fuzzy Synthetic Evaluation (FSE)}

In considering the complex system of vulnerability, we need to consider a total of nine factors, and the nine sub-factors belong to three different categories, in order to obtain good evaluation results, we use fuzzy analytic hierarchy process.

- $\quad$ Build Index System U

First of all, in the second-level indicators, we establish the factor universe U.

$$
U=\left\{u_{1}, u_{2}, u_{3}\right\}
$$

Among them, u1 represents EI, $\mathrm{u} 2$ represents PI, $\mathrm{u} 3$ represents SI

Second, in the three indicators, we establish the corresponding evaluation object factor.

$$
U_{i}=\left\{u_{i}^{(1)}, u_{i}^{(2)}, u_{i}^{(3)}\right\} \quad i=1,2,3
$$

- $\quad$ Determine Mark Set V

For the third level of the indicators, we hope that experts scoring them separately, up to 10 points, a minimum of 0 points, the lower the score that this factor contributes more to the healthy and stable development of secondary indicators. To this end, we designed the following.

$$
c_{i}=\frac{\text { The ranking of the country }}{\text { The total number of countries }} \times 10
$$

The rankings here refer to the world rankings given by the relevant organizations in the world about the fair and reliable element of Xi. Here's the ranking, we assume that they are based on the factor $\mathrm{Xi}$ from the good start to sort. These indicators are gathered by experts and scholars from various countries, analysis, verification of the relevant data derived. Therefore, we can use this formula to simulate expert scoring.

- Calculate Fuzzy Relation Matrix R

We transform the indicators $\mathrm{X} 1, \mathrm{X} 2 \ldots \mathrm{X} 9$ into quantitatively calculable values, and then we construct their membership functions according to the construction method of quantitative indexes. The function is constructed as follows:

$$
f_{A}\left(c_{i}\right)=\left\{\begin{array}{ll}
0 & c_{i} \geq z_{2} \\
\frac{z_{2}-c_{i}}{z_{2}-z_{1}} & z_{1}<c_{i}<z_{2} \\
1 & c_{i} \leq z_{1}
\end{array} f_{B}\left(c_{i}\right)=\left\{\begin{array}{ll}
0 & c_{i} \geq u_{3} \\
\frac{z_{3}-c_{i}}{z_{3}-z_{2}} & z_{2} \leq c_{i}<z_{3} \\
\frac{c_{i}-z_{2}}{z_{3}-z_{2}} & z_{1}<c_{i}<z_{2} \\
0 & c_{i} \leq z_{1}
\end{array} f_{c}\left(c_{i}\right)= \begin{cases}1 & c_{i} \geq z_{3} \\
\frac{c_{i}-z_{2}}{z_{3}-z_{2}} & z_{2}<c_{i}<z_{3} \\
0 & c_{i} \leq z_{2}\end{cases}\right.\right.
$$


Among them, they are three thresholds respectively. These three thresholds are based on the criteria of stability, vulnerability and vulnerability divided by FSI.

According to these three membership functions, we can get fuzzy relation matrix Ri, the form is as follows:

$$
R_{i}=\left(\begin{array}{ccc}
r_{11} & r_{12} & r_{13} \\
r_{21} & r_{22} & r_{23} \\
r_{31} & r_{32} & r_{33}
\end{array}\right)
$$

Where rij is the membership of the element in Ui for evaluating $\mathrm{Vj}$ in the domain $\mathrm{V}$

- Construct Judgment Matrix

We compare X1, X2 and X3 with each other for a total of 3 times.

Calculated: maximum eigenvalue $=3.0183$

- Conduct Consistency Checks and Calculate Combined Weight

Calculate the consistency index CI, the average consistency index RI

Calculate the consistency ratio $\mathrm{CR}$

$$
C I=\frac{\lambda_{\max }-n}{n-1} \quad R I=\frac{\lambda_{\max }^{\prime}-n}{n-1}
$$

$$
C R=\frac{C I}{R I}
$$

From the above, $\mathrm{CI}=0.0091, \mathrm{CR}=0.0176 . \mathrm{CR}<0.1$, then the consistency of judgment matrix is acceptable. EI weight.

Through the above method, we can get SI weight $w_{2}=(0.1396,0.5278,0.3325)$, PI weigh $w_{3}=(0.5499,0.2402,0.2098)$.

Our group collected data on the factors affecting Yemen for the past five years (2011-2015) and calculated the FDS with and without climate change, respectively.

Table 1 The Value of FDS with / without climate impact
Year
FDS with Climate Impact
FDS without Climate Impact

\begin{tabular}{lll}
\hline 2011 & 8.4882 & 8.4677 \\
2012 & 8.3685 & 8.3128 \\
2013 & 8.4052 & 8.2567 \\
2014 & 8.4382 & 8.2156 \\
2015 & 8.5201 & 8.2354 \\
\hline
\end{tabular}

From Table 1, it can be concluded that the value of Table is less than that of climate change without climate change. This shows that climate change makes a country more vulnerable to some extent.

In order to reduce the influence of subjective factors and improve the accuracy of evaluation results, we use sensitivity analysis method to study the influence of the change of judgment matrix in AHP (Analytic hierarchy process) on the evaluation results. The change range is about 0.0055 , which is far less than 0.1 , which is within acceptable range.

\section{References}

[1]. wikipedia,Retrieved from:https://en.wikipedia.org/wiki/Somalia.

[2]. Central Bank of Somalia-Economy and Finance". Somalbanca.org.Archived from the original on 24January 2009.Retrieved 30 December 2010. 
[3]. World population Prospects: The 2017 Revesion.ESA.UN.org (custom data acquired via website). United Nations Department of Economic and Social Affairs, Population Division. Retrieved 10 September 2017. 